\title{
Synthesis of a new generation of amphiphiles with multi-cryptand headgroups: A comparative study at air-water interface
}

\author{
B SARKAR, R K GUPTA ${ }^{\dagger}, \mathrm{R}$ A SINGH ${ }^{\dagger}$ and P K BHARADWAJ* \\ Department of Chemistry, Indian Institute of Technology, Kanpur 208 016, India \\ ${ }^{\dagger}$ Department of Chemistry, Faculty of Science, Banaras Hindu University, Varanasi 221 005, India
}

\begin{abstract}
A laterally non-symmetric aza cryptand has been derivatized with two hydrophobic chains to afford amphiphiles with one cryptand headgroup and two hydrophobic tails. Three such units readily attach to 1,3,5benzenetricarbonyl trichloride, to form a new generation of amphiphilic molecules with three cryptand headgroups and six hydrophobic chains. These molecules are studied at the air-water interface in a Langmuir trough. They readily form LB-films on a number of substrates that are characterized.
\end{abstract}

Keywords. Cryptand; amphiphiles; Langmuir isotherm; monolayers; LB film; AFM.

\section{Introduction}

Amphiphilic molecules are crucial to life starting from cell walls to translocation of biomolecules in vivo. They are also found to be quite useful in the synthesis of nanosized materials (Foerster and Antonietti 1998; Lazzari et al 2006) besides offering a key in developing new types of functionalized materials. Synthetic amphiphiles are known to form stable monolayers at the air-water interface in a Langmuir trough that can be transferred through LB technique (Ulman 1991) to construct highly ordered monolayer or multilayered ultra-thin films of molecular dimension. This technique has assumed greater importance in recent times with the current demand for materials with tailored interfacial properties. A number of functionalities can be introduced in the films through the amphiphiles. Amphiphiles of high molecular weight are preferred over low molecular weight compounds due to enhanced stability of the former. These supramolecular systems should be of importance in (i) applications such as chemical sensors, (ii) understanding molecular interactions on biological cell surfaces (Ijiro et al 2002; Nakane and Kubo 2004), (iii) developing novel two-dimensional molecular assemblies composed of multiple chemical species and (iv) developing non-linear optical materials (Le Bouder et al 2003). Naturally, a large number of synthetic amphiphiles with cyclic or acyclic headgroups and one or more hydrophobic tails have been reported in the literature. Herein, we report synthesis of a number of cryptand based amphiphilic molecules that provide a new generation of synthetic amphiphiles. Studies presented herein are aimed at probing the formation of mono- as well as multi-layer films with the synthesized amphiphiles. The optimal parameters for

\footnotetext{
*Author for correspondence (pkb@iitk.ac.in)
}

stable LB films can be obtained from such studies that are required before embarking on a research to make new materials in the form of thin films.

\section{Experimental}

\subsection{Materials}

The cryptand-based amphiphiles were prepared in multi steps. The cryptand, $\mathbf{L}_{\mathrm{o}}$, was synthesized as reported earlier (Ragunathan and Bharadwaj 1992). Reagent-grade anhydrous sodium sulphate, sodium carbonate and trifluoroacetic acid were received from S.D. Fine Chemicals (India). All the solvents (SD Fine Chemicals) were purified prior to use. Chromatographic purification was achieved by column chromatography using silica gel (100-200 mesh) obtained from Acme Synthetic Chemicals, India. All acid chlorides were obtained from Aldrich (USA). Solvents for making solutions for spreading in trough were prepared with spectroscopic grade solvents purchased from Merck (India) Ltd. Pure water was used as sub-phase obtained from SD Fine Chemicals (India).

\subsection{Analysis and measurements}

The spectroscopic data were collected as follows: ${ }^{1} \mathrm{H}-$ NMR and ${ }^{13} \mathrm{C}$-NMR on a JEOL JNM-LA400 FT (400 and $100 \mathrm{MHz}$, respectively); mass spectra with JEOL SX 102/DA-6000 FAB-mass or Spec-2E MALDI-TOF mass spectrometer; melting points on an electrical melting point apparatus by PERFIT; elemental analyses from the CDRI, Lucknow, India. For monolayer and LB studies, the sub-phase used was either de-ionized water (resistivity, $18.2 \mathrm{M} \Omega \mathrm{cm}$ ), $1 \mathrm{~N} \mathrm{HCl}$ or $1 \mathrm{~N} \mathrm{NaOH}$ in de-ionized water. The $\Pi-\mathrm{A}$ isotherms were obtained with computer-controlled 
Nima LB Trough (Nima Technology Ltd., England). The instrument was mounted inside a dust-free acrylic box. Reliability of the instrumental set-up was confirmed by examining monolayer compression and expansion curves of stearic acid (Sigma Chemical Co., USA). The minimum area per molecule obtained in our set-up was very similar to the literature (Abraham et al 1981) value of $20.4 \AA^{2}$ / molecule. Clean quartz plates were used as substrates for deposition of monolayers. The monolayers were transferred onto the substrates by vertical dipping method. The morphology of the LB film deposited on glass substrates was probed with an atomic force microscope (Molecular Imaging, USA). Surface profiler talystep (Alpha-Step 500 KLA Tencor) was used to measure thickness of the thin films.

\subsection{Synthesis of double-tailed amphiphiles}

The synthetic methodology is shown in scheme 1 . The mono-BOC protected cryptand, $\mathbf{L}_{1}(0.13 \mathrm{~g}, 0.2 \mathrm{mmol})$, was dissolved in $30 \mathrm{ml}$ of dry THF. To this, a THF solution $(30 \mathrm{ml})$ of triethylamine $(0.5 \mathrm{mmol})$ and acyl chloride $(1 \mathrm{mmol})$ was added drop wise over a period of $30 \mathrm{~min}$ with constant stirring at $5^{\circ} \mathrm{C}$ under dinitrogen. After the addition was complete, the reaction mixture was allowed to come to room temperature and stirred for $6 \mathrm{~h}$ and then refluxed for $2 \mathrm{~h}$ to complete the reaction. The solvent was then evaporated off to get an oily mass. This was extracted with chloroform $(100 \mathrm{ml})$, washed with water $(3 \times 100 \mathrm{ml})$, dried over anhydrous sodium sulphate and finally evaporated to dryness. The yellowish oily residue dissolved in THF ( $5 \mathrm{ml}), 2 \mathrm{ml}$ of trifluoroacetic acid was added and allowed to stir for $12 \mathrm{~h}$ at $R T$, to remove the BOCprotection. It was then neutralized with saturated aqueous solution of sodium bicarbonate, treated with sodium chloride and extracted with chloroform $(2 \times 50 \mathrm{ml})$. The chloroform layer was washed well with water $(4 \times 100 \mathrm{ml})$, dried over anhydrous sodium sulphate and evaporated to dryness to get the desired compound as a light brown oil. Further purification could be achieved by washing with dichloromethane: petroleum ether $(1: 5 \mathrm{v} / \mathrm{v})$.

2.3a Bis-decanoyl derivative of cryptand $\left(L_{4}\right)$ : Yield: 0.13 g (74\%); FAB-MS: $m / z 869$ (100\%) [M] ${ }^{+} . .{ }^{1} \mathrm{H}-\mathrm{NMR}$ :
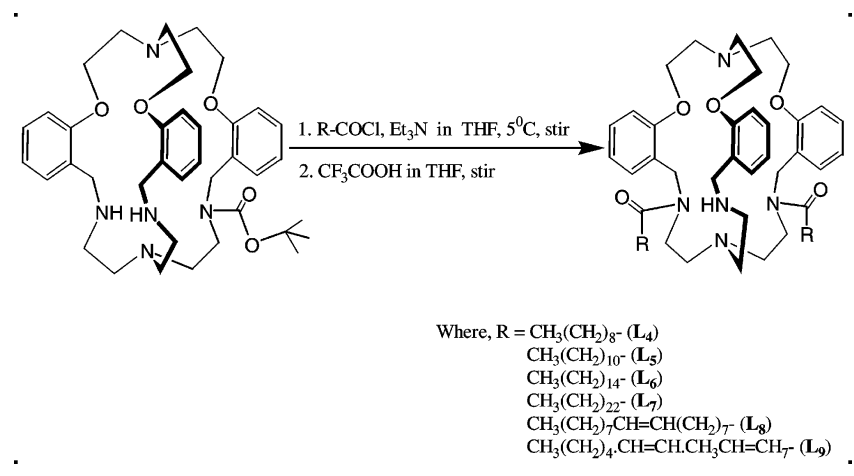

Scheme 1.
(400 MHz, $\left.\mathrm{CDCl}_{3}, 25^{\circ} \mathrm{C}, \mathrm{TMS}\right): \delta 0 \cdot 9(t, 6 \mathrm{H}), 1 \cdot 3(m, 28$ $\mathrm{H}), 2(b r s, 1 \mathrm{H}), 2 \cdot 5(m, 4 \mathrm{H}), 2 \cdot 6(b r s, 4 \mathrm{H}), 2 \cdot 8(b r s$, $4 \mathrm{H}), 3 \cdot 1(b r s, 2 \mathrm{H}), 3 \cdot 6(m, 10 \mathrm{H}), 4 \cdot 2(b r s, 2 \mathrm{H}), 4 \cdot 6(b r s$, $4 \mathrm{H}), 5.0(b r s, 4 \mathrm{H}), 7(m, 12 \mathrm{H})$. Anal. calcd. for $\mathrm{C}_{53} \mathrm{H}_{81} \mathrm{~N}_{5} \mathrm{O}_{5}$ : C, 73.32; H, 9.40; N, 8.07\%. Found: C, 73.81; H, 9.09; N, 7.89\%.

2.3b Bis-dodecanoyl derivative of cryptand ( $\left.L_{5}\right)$ : Yield: $0.36 \mathrm{~g}$ (78\%); FAB-MS: $m / z 925$ (100\%) $[\mathrm{M}]^{+}$. ${ }^{1} \mathrm{H}-\mathrm{NMR}:\left(400 \mathrm{MHz}, \mathrm{CDCl}_{3}, 25^{\circ} \mathrm{C}\right.$, TMS): $\delta 0.9(t, 6 \mathrm{H})$, $1 \cdot 3(m, 36 \mathrm{H}), 2(b r s, 1 \mathrm{H}), 2 \cdot 5(m, 4 \mathrm{H}), 2 \cdot 6(b r s, 4 \mathrm{H})$, $2 \cdot 8(b r s, 4 \mathrm{H}), 3 \cdot 1(b r s, 2 \mathrm{H}), 3 \cdot 6(m, 10 \mathrm{H}), 4 \cdot 3(b r s, 2 \mathrm{H})$, $4.7(b r s, 4 \mathrm{H}), 5(b r s, 4 \mathrm{H}), 7(m, 12 \mathrm{H})$. Anal. calcd. for $\mathrm{C}_{57} \mathrm{H}_{89} \mathrm{~N}_{5} \mathrm{O}_{5}$ : C, 74.06; H, 9.70; N, 7.58\%. Found: C, $74 \cdot 86 ; \mathrm{H}, 9 \cdot 52 ; \mathrm{N}, 7 \cdot 27 \%$.

2.3c Bis-palmitoyl derivative of cryptand $\left(L_{6}\right)$ : Yield: $0.38 \mathrm{~g}$ (74\%); FAB-MS: $m / z 1037$ (100\%) [M] $]^{+} .{ }^{1} \mathrm{H}-$ NMR (400 MHz, $\left.\mathrm{CDCl}_{3}, 25^{\circ} \mathrm{C}, \mathrm{TMS}\right): \delta 0.9(t, 6 \mathrm{H}), 1 \cdot 3$ $(m, 52 \mathrm{H}), 2(b r s, 1 \mathrm{H}), 2.5(m, 4 \mathrm{H}), 2 \cdot 6(b r s, 4 \mathrm{H}), 2 \cdot 8(b r$ $s, 4 \mathrm{H}), 3 \cdot 2(b r s, 2 \mathrm{H}), 3 \cdot 6(m, 10 \mathrm{H}), 4 \cdot 3(b r s, 2 \mathrm{H}), 4 \cdot 6(b r$ $s, 4 \mathrm{H}), 5(b r s, 4 \mathrm{H}), 7(m, 12 \mathrm{H})$. Anal. calcd. for $\mathrm{C}_{65} \mathrm{H}_{105} \mathrm{~N}_{5} \mathrm{O}_{5}$ : C, $75 \cdot 32 ; \mathrm{H}, 10 \cdot 21 ; \mathrm{N}, 6 \cdot 76 \%$. Found: $\mathrm{C}$, 74.86; H, 9.94; N, 6.68\%.

$2.3 \mathrm{~d}$ Bis-biphenoyl derivative of cryptand $\left(L_{7}\right)$ : Yield: $0.42 \mathrm{~g}$ (70\%); FAB-MS: $m / z \quad 1205$ (100\%) [M] $]^{+} .{ }^{1} \mathrm{H}-$ NMR: $\left(400 \mathrm{MHz}, \mathrm{CDCl}_{3}, 25^{\circ} \mathrm{C}, \mathrm{TMS}\right): \delta 0 \cdot 9(t, 6 \mathrm{H}), 1 \cdot 3$ $(m, 74 \mathrm{H}), 2(b r s, 1 \mathrm{H}), 2 \cdot 5(m, 4 \mathrm{H}), 2 \cdot 6(b r s, 4 \mathrm{H}), 2 \cdot 8(b r$ $s, 4 \mathrm{H}), 3 \cdot 2(b r s, 2 \mathrm{H}), 3 \cdot 6(m, 10 \mathrm{H}), 4 \cdot 3(b r s, 2 \mathrm{H}), 4 \cdot 6(b r$ $s, 4 \mathrm{H}), 5 \cdot 1(b r s, 4 \mathrm{H}), 7(m, 12 \mathrm{H})$. Anal. calcd. for $\mathrm{C}_{77} \mathrm{H}_{129} \mathrm{~N}_{5} \mathrm{O}_{5}$ : C, 76.76; H, 10.79; N, 5.81\%. Found: C, $76 \cdot 47 ; \mathrm{H}, 10 \cdot 66 ; \mathrm{N}, 5 \cdot 85 \%$.

2.3e Bis-oleoyl derivative of cryptand $\left(L_{8}\right)$ : Yield: $0.38 \mathrm{~g}(70 \%)$; FAB-MS: $m / z \quad 1089$ (100\%) [M] $]^{+} .{ }^{1} \mathrm{H}-$ NMR: $\left(400 \mathrm{MHz}, \mathrm{CDCl}_{3}, 25^{\circ} \mathrm{C}, \mathrm{TMS}\right): \delta 0.9(b r s, 6 \mathrm{H})$, $1 \cdot 3(b r s, 44 \mathrm{H}), 2(b r s, 9 \mathrm{H}), 2 \cdot 6(m, 8 \mathrm{H}), 2 \cdot 8(b r s, 2 \mathrm{H})$, $3 \cdot 2(b r s, 2 \mathrm{H}), 3 \cdot 5(m, 12 \mathrm{H}), 4 \cdot 1(b r s, 2 \mathrm{H}), 4 \cdot 6(b r s, 4 \mathrm{H})$, $5(b r s, 4 \mathrm{H}), 5.4(b r s, 4 \mathrm{H}), 7(m, 12 \mathrm{H})$. Anal. calcd. for $\mathrm{C}_{69} \mathrm{H}_{109} \mathrm{~N}_{5} \mathrm{O}_{5}$ : C, 76.13; H, 10.09; N, 6.43\%. Found: C, 75.67; H, 9.89; N 6.59\%.

2.3f Bis-linoleoyl derivative of cryptand $\left(L_{9}\right)$ : Yield: $0.36 \mathrm{~g}$ (68\%); FAB-MS: $m / z 1085$ (100\%) [M] ${ }^{+} .{ }^{1} \mathrm{H}-$ NMR: $\left(400 \mathrm{MHz}, \mathrm{CDCl}_{3}, 25^{\circ} \mathrm{C}, \mathrm{TMS}\right): \delta 0.9(b r s, 6 \mathrm{H})$, $1 \cdot 3(m, 32 \mathrm{H}), 2(b r s, 9 \mathrm{H}), 2 \cdot 6(m, 12 \mathrm{H}), 2 \cdot 8(b r s, 2 \mathrm{H})$, $3 \cdot 2(b r s, 2 \mathrm{H}), 3 \cdot 5(m, 12 \mathrm{H}), 4 \cdot 1(b r s, 2 \mathrm{H}), 4 \cdot 6(b r s, 4 \mathrm{H})$, $5(b r s, 4 \mathrm{H}), 5.4(b r s, 8 \mathrm{H}), 7(m, 12 \mathrm{H})$. Anal. calcd. for $\mathrm{C}_{69} \mathrm{H}_{105} \mathrm{~N}_{5} \mathrm{O}_{5}$ : C, 76.41; H, 9.76; N, 6.46\%. Found: $\mathrm{C}$, $75 \cdot 83 ; \mathrm{H}, 9 \cdot 63 ; \mathrm{N}, 6 \cdot 24 \%$.

\subsection{Synthesis of hexa-tailed amphiphiles}

The hexa-tailed amphiphiles were synthesized by reacting the double-tailed amphiphiles $\left(\mathbf{L}_{4}-\mathbf{L}_{9}\right)$ with 1,3,5-benzene- 
tricarbonyl trichloride in $\mathrm{THF}$ at $5^{\circ} \mathrm{C}$ in $3: 1$ molar ratio under moderate dilution in presence of triethylamine as illustrated in scheme 2 .

The compounds thus prepared, were further purified by precipitating from chloroform solution upon adding hexane.

2.4a Decanoyl derivatized tri-cryptand amphiphile $\left(L_{10}\right)$ : Yield: $0.56 \mathrm{~g} \quad(68 \%)$; MALDI-TOF-MS: $\mathrm{m} / \mathrm{z}$ $2760.58[\mathrm{M}]^{+} .{ }^{1} \mathrm{H}-\mathrm{NMR}\left(400 \mathrm{MHz}, \mathrm{CDCl}_{3}, 25^{\circ} \mathrm{C}, \mathrm{TMS}\right)$ : $\delta 0.80(b r s, 18 \mathrm{H}), 0.99-1.19(m, 60 \mathrm{H}), 1.32(m, 12 \mathrm{H})$, $1.56(\mathrm{~m}, 12 \mathrm{H}), 2.24(\mathrm{~m}, 12 \mathrm{H}), 2.53(\mathrm{br} s, 18 \mathrm{H}), 3.05(\mathrm{~m}$, $18 \mathrm{H}), 3.27(m, 18 \mathrm{H}), 4 \cdot 12(b r s, 18 \mathrm{H}), 4.95(t, 18 \mathrm{H})$, 6.71-7.2 (m, 36H, aromatic), $7.74(s, 3 \mathrm{H})$. Anal. calcd. for $\mathrm{C}_{168} \mathrm{H}_{243} \mathrm{~N}_{15} \mathrm{O}_{18}$ : C, 73.09; H, 8.87; N, 7.61\%. Found: C, $72 \cdot 39 ; \mathrm{H}, 8 \cdot 45 ; \mathrm{N}, 7 \cdot 32 \%$.

2.4b Dodecanoyl derivatized tri-cryptand amphiphile $\left(L_{11}\right)$ : Yield: $0.57 \mathrm{~g}$ (65\%); MALDI-TOF-MS: $\mathrm{m} / \mathrm{z}$ 2928.64 [M] ${ }^{+} .{ }^{1} \mathrm{H}-\mathrm{NMR}:\left(400 \mathrm{MHz}, \mathrm{CDCl}_{3}, 25^{\circ} \mathrm{C}, \mathrm{TMS}\right)$ : $\delta 0.80(b r s, 18 \mathrm{H}), 1 \cdot 0-1 \cdot 19(m, 84 \mathrm{H}), 1.32(m, 12 \mathrm{H})$, $1.56(\mathrm{~m}, 12 \mathrm{H}), 2.24(\mathrm{~m}, 12 \mathrm{H}), 2.53(\mathrm{br} \mathrm{s}, 18 \mathrm{H}), 3.05(\mathrm{~m}$, $18 \mathrm{H}), 3.27$ ( $m, 18 \mathrm{H}), 4 \cdot 12$ (br s, 18H), $4.95(t, 18 \mathrm{H}), 6 \cdot 71-$ $7.2(m, 36 \mathrm{H}$, aromatic), $7.75(s, 3 \mathrm{H})$. Anal. calcd. for $\mathrm{C}_{180} \mathrm{H}_{267} \mathrm{~N}_{15} \mathrm{O}_{18}: \mathrm{C}, 73 \cdot 81 ; \mathrm{H}, 9 \cdot 18 ; \mathrm{N}, 7 \cdot 17 \%$. Found: $\mathrm{C}$, 72.95; H, 9.03; N, 6.91\%.

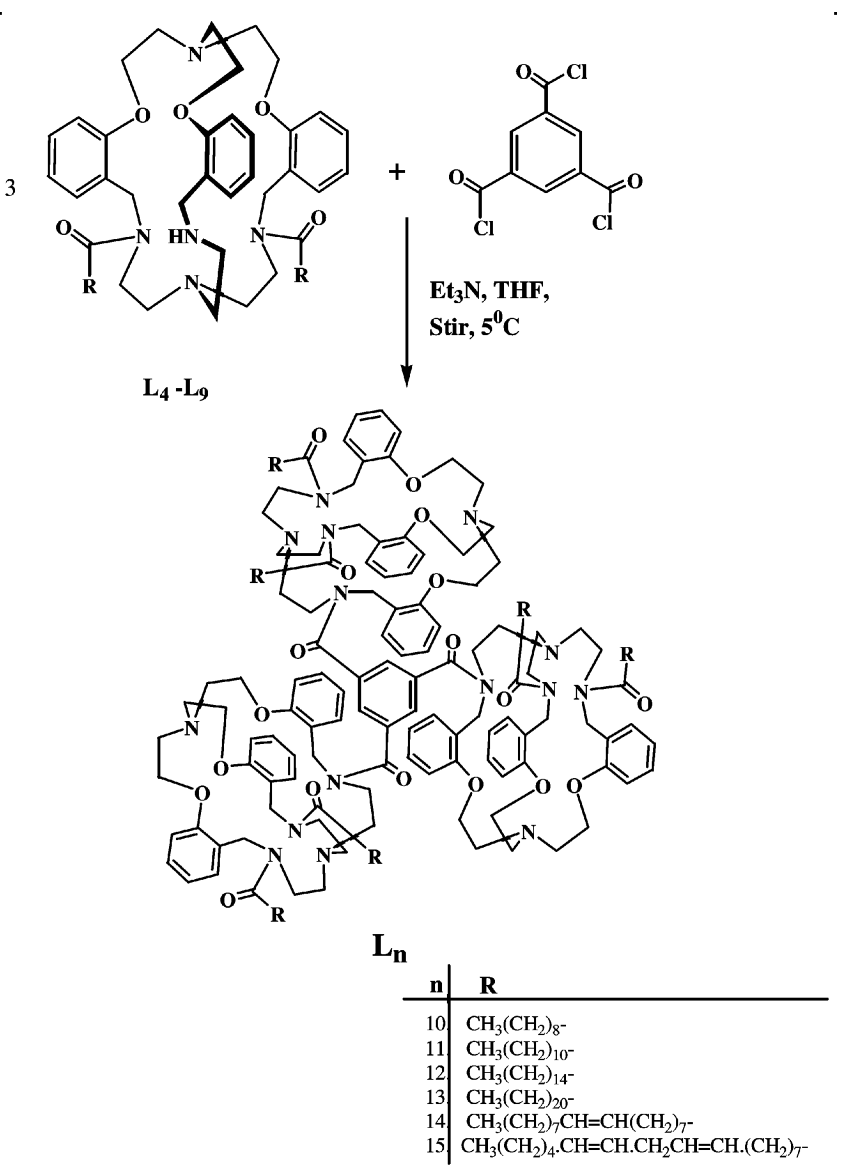

Scheme 2. 2.4c Palmitoyl derivatized tri-cryptand amphiphile $\left(L_{12}\right)$ : Yield: $0.64 \mathrm{~g}$ (66\%); MALDI-TOF-MS: $\mathrm{m} / \mathrm{z}$ $3265.8[\mathrm{M}]^{+} .{ }^{1} \mathrm{H}-\mathrm{NMR}:\left(400 \mathrm{MHz}, \mathrm{CDCl}_{3}, 25^{\circ} \mathrm{C}, \mathrm{TMS}\right)$ : $\delta 0.80(b r s, 18 \mathrm{H}), 1-1.20(m, 132 \mathrm{H}), 1.32(b r s, 12 \mathrm{H})$, $1.53(\mathrm{~m}, 12 \mathrm{H}), 2.27(\mathrm{~m}, 12 \mathrm{H}), 2.56(\mathrm{br} \mathrm{s}, 18 \mathrm{H}), 3.05(\mathrm{~m}$, $18 \mathrm{H}), 3.25(m, 18 \mathrm{H}), 4.20(b r s, 18 \mathrm{H}), 4.95(m, 18 \mathrm{H})$, $6 \cdot 72-7.25(m, 36 \mathrm{H}$, aromatic), $7.75(s, 3 \mathrm{H})$. Anal. calcd. for $\mathrm{C}_{204} \mathrm{H}_{315} \mathrm{~N}_{15} \mathrm{O}_{18}$ : C, 75.03; H, 9.72; N, 6.43\%. Found: C, $74 \cdot 23 ; \mathrm{H}, 9 \cdot 39 ; \mathrm{N}, 6 \cdot 19 \%$.

$2.4 \mathrm{~d}$ Biphenoyl derivatized tri-cryptand amphiphile $\left(L_{13}\right)$ : Yield: $0.68 \mathrm{~g}$ (60\%); MALDI-TOF-MS: $\mathrm{m} / \mathrm{z}$ $3770 \cdot 8[\mathrm{M}]^{+} .{ }^{1} \mathrm{H}-\mathrm{NMR}:\left(400 \mathrm{MHz}, \mathrm{CDCl}_{3}, 25^{\circ} \mathrm{C}, \mathrm{TMS}\right)$ : $\delta 0.80(b r s, 18 \mathrm{H}), 1-1.20(m, 204 \mathrm{H}), 1.32(b r s, 12 \mathrm{H})$, $1.56(\mathrm{~m}, 12 \mathrm{H}), 2.24(\mathrm{~m}, 12 \mathrm{H}), 2.56(\mathrm{br} \mathrm{s}, 18 \mathrm{H}), 3.07$ ( $m$, $18 \mathrm{H}), 3.25(m, 18 \mathrm{H}), 4.20(b r s, 18 \mathrm{H}), 4.95(m, 18 \mathrm{H})$, $6 \cdot 72-7.25(m, 36 \mathrm{H}$, aromatic), $7.75(s, 3 \mathrm{H})$. Anal. calcd. for $\mathrm{C}_{240} \mathrm{H}_{387} \mathrm{~N}_{15} \mathrm{O}_{18}: \mathrm{C}, 76 \cdot 45 ; \mathrm{H}, 10 \cdot 34 ; \mathrm{N}, 5.57 \%$. Found: C, $75.61 ; \mathrm{H}, 9.97 ; \mathrm{N}, 5 \cdot 35 \%$.

$2.4 \mathrm{e}$ Oleoyl derivatized tri-cryptand amphiphile $\left(L_{14}\right)$ : Yield: $0.61 \mathrm{~g}$ (60\%); MALDI-TOF-MS: $\mathrm{m} / \mathrm{z} \quad 3422.3$ $[\mathrm{M}]^{+} .{ }^{1} \mathrm{H}-\mathrm{NMR}\left(400 \mathrm{MHz}, \mathrm{CDCl}_{3}, 25^{\circ} \mathrm{C}, \mathrm{TMS}\right): \delta 0 \cdot 80$ (br $s, 18 \mathrm{H}), 0.98-1.34(m, 120 \mathrm{H}), 1.58$ (br s, 12H), 2.23 (br s, 36H), $2.53(m, 18 \mathrm{H}), 2.75(m, 18 \mathrm{H}), 3.25(m, 18 \mathrm{H})$, $4 \cdot 15$ (br s, 18H), 4.90 (br s, 18H), 5.41 (br s, 24H), 6.72$7 \cdot 25(\mathrm{~m}, 36 \mathrm{H}$, aromatic), $7 \cdot 80(\mathrm{~s}, 3 \mathrm{H})$. Anal. calcd. for $\mathrm{C}_{216} \mathrm{H}_{327} \mathrm{~N}_{15} \mathrm{O}_{18}: \mathrm{C}, 5.81 ; \mathrm{H}, 9.63 ; \mathrm{N}, 6 \cdot 14 \%$. Found: $\mathrm{C}$, $74 \cdot 99 ; \mathrm{H}, 9 \cdot 28$; N $5 \cdot 91 \%$.

$2.4 \mathrm{f}$ Linoleoyl derivatized tri-cryptand amphiphile $\left(L_{15}\right)$ : Yield: $0.59 \mathrm{~g}$ (58\%); MALDI-TOF-MS: $\mathrm{m} / \mathrm{z}$ $3410 \cdot 1[\mathrm{M}]^{+} .{ }^{1} \mathrm{H}-\mathrm{NMR}\left(400 \mathrm{MHz}, \mathrm{CDCl}_{3}, 25^{\circ} \mathrm{C}, \mathrm{TMS}\right): \delta$ $0.80(b r s, 18 \mathrm{H}), 1-1.33(m, 84 \mathrm{H}), 1.54(b r s, 12 \mathrm{H}), 1.97$ (br s, 36H), $2.56(m, 30 \mathrm{H}), 2.72(m, 18 \mathrm{H}), 3.29(m, 18 \mathrm{H})$, $4 \cdot 11(b r s, 18 \mathrm{H}), 4.90(b r s, 18 \mathrm{H}), 5 \cdot 27$ (br s, 48H), 6.72$7.20(m, 36 \mathrm{H}$, aromatic), $7.78(s, 3 \mathrm{H})$. Anal. calcd. for $\mathrm{C}_{216} \mathrm{H}_{315} \mathrm{~N}_{15} \mathrm{O}_{18}$ : C, 76.08; H, 9.31; N, 6.16\%. Found: C, $75 \cdot 41 ; \mathrm{H}, 9 \cdot 04 ; \mathrm{N}, 5 \cdot 96 \%$.

\section{Results and discussion}

Synthesis of the amphiphiles in moderate yields suggests that the route adopted for the syntheses is a viable one and many more such molecules can be designed and synthesized. The ${ }^{1} \mathrm{H}-\mathrm{NMR}$ spectra of the amphiphiles and cryptand units are consistent with their structures and the FAB or MALDI-TOF mass spectra exhibit the molecular ion peak in all cases. Hence the amphiphiles behave as robust molecules and can be handled with ease without decomposition.

\subsection{Monolayer study}

The pattern of the isotherms for the double-tailed amphiphiles and hexa-tailed amphiphiles are shown in figure 1 

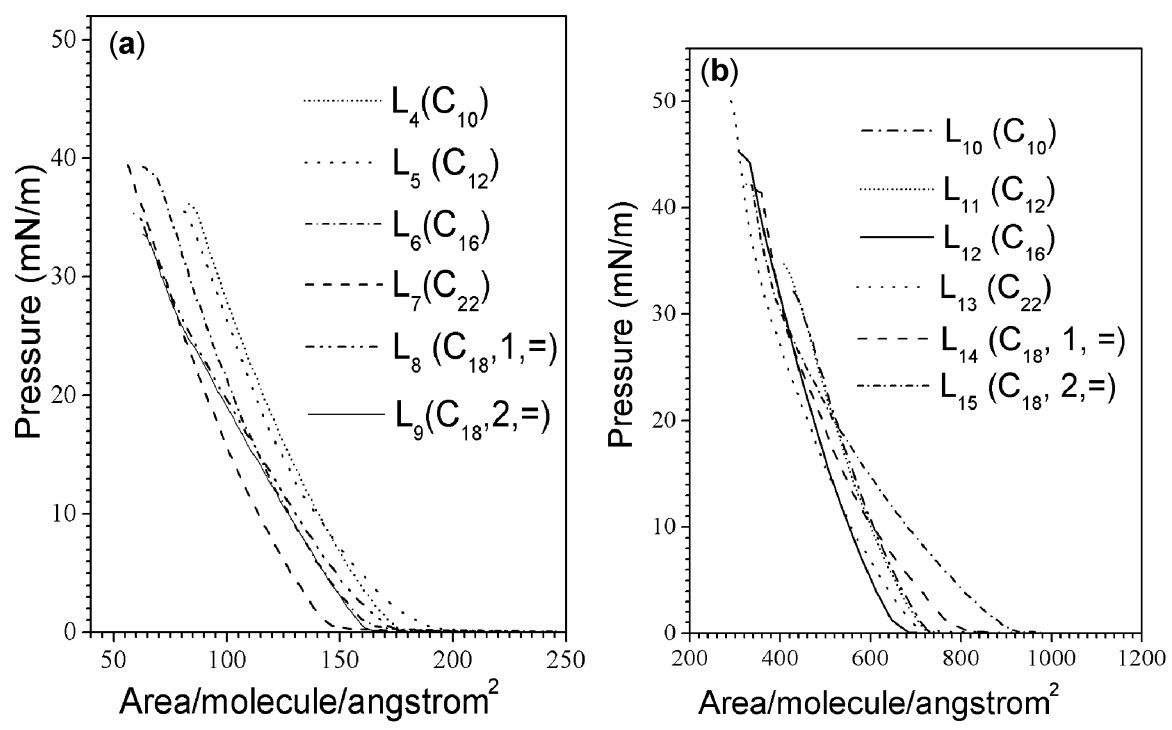

Figure 1. Graphical representation of pressure-area ( $-\mathrm{A})$ isotherms of monolayers formed by (a) double-tailed and (b) hexa-tailed amphiphiles at air-water interface.

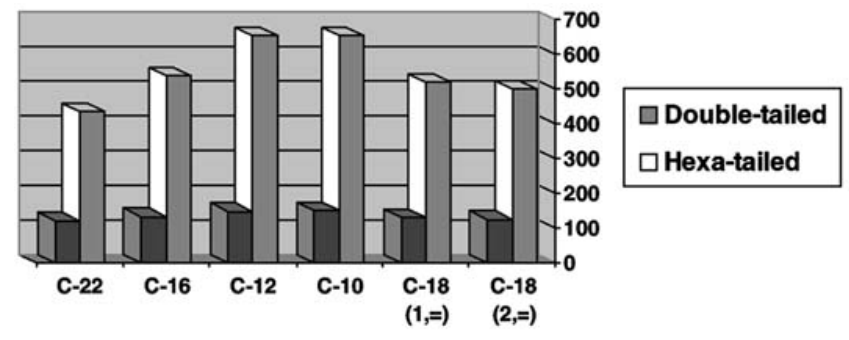

Figure 2. Bar chart for comparison of limiting area $\left(\AA^{2}\right)$ per molecule for double-tailed $\left(\mathbf{L}_{4}-\mathbf{L}_{9}\right)$ and hexa-tailed $\left(\mathbf{L}_{10}-\mathbf{L}_{15}\right)$ amphiphiles.

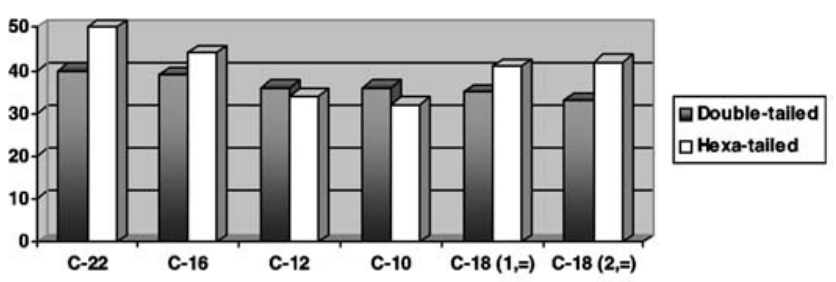

Figure 3. Bar chart for comparison of maximum surface pressure $\left(\mathrm{mNm}^{-1}\right)$ sustained for double-tailed $\left(\mathbf{L}_{4}-\mathbf{L}_{9}\right)$ and hexatailed $\left(\mathbf{L}_{10}-\mathbf{L}_{15}\right)$ amphiphiles.

and illustrated in bar charts (figures 2 and 3 ) when the subphase is pure water. While most of the isotherms consist of gaseous, liquid expanded and liquid condensed phases, a number of isotherms did not show any distinct phase changes. However, no well-defined solid phase can be observed. The behaviours of the monolayers are reproducible in all the cases and several generalizations can be made.
In case of double-tailed amphiphiles $\left(\mathbf{L}_{4}-\mathbf{L}_{9}\right)$, the presence of well-defined liquid expanded phase indicates that there is a strong repulsion between the cryptand headgroups under compression. When the amphiphiles are compressed further then phase transition from liquid expanded phase to liquid condensed phase is observed around 28$35 \mathrm{mN} / \mathrm{m}$ in all cases. This phase transition indicates that when these amphiphiles are forced to come closer there starts hydrogen-bonding interactions between the secondary amino group of the cryptand head-group and the carbonyl group of the neighbouring amphiphile. Besides, van der Waals interactions between the hydrocarbon chains also begin to dominate. Interestingly, compared to the case of amphiphiles with three hydrophobic tails (Das et al 1997, 2000), the single tail amphiphiles can sustain significantly higher surface pressure and double-tailed amphiphiles lie in between them. As a comparison, the tri-palmitoyl derivative of the cryptand can sustain up to $25 \mathrm{mNm}^{-1}$ and the mono-palmitoyl derivative can sustain about $45 \mathrm{mNm}^{-1}$, the di-palmitoyl derivative can sustain up to $36 \mathrm{mNm}^{-1}$ of surface pressure. The other double chain cryptands can sustain surface pressure between 33 and $40 \mathrm{mNm}^{-1}$ whereas mono derivatives can sustain in the range $40-50 \mathrm{mNm}^{-1}$. This indicates that packing of alkyl chains in di-derivatives lies somewhere in between triand mono-derivatives. In case of mono-derivatives, hydrogen bonding between the two free $\mathrm{NH}$ groups and the CO-group of the neighbour can also lead to the higher stabilization of the monolayer under high surface pressure, which is also the case for double-tailed amphiphiles.

In case of hexa-tailed amphiphiles, maximum sustainable pressure varied from $32-50 \mathrm{mNm}^{-1}$ (table 1 ). For C10 and $\mathrm{C}-12$ chain length, the hexa-tailed ones can sustain $\sim 2 \mathrm{mNm}^{-1}$ less pressure than their double-tailed counter- 
Table 1. Tabular representation of limiting area $\left(\AA^{2}\right) /$ molecule and maximum pressure sustained for the double-tailed amphiphiles $\left(\mathbf{L}_{4}-\mathbf{L}_{9}\right)$ and tri-cryptand based hexa-tailed amphiphiles $\left(\mathbf{L}_{10}-\mathbf{L}_{15}\right)$.

\begin{tabular}{|c|c|c|c|c|}
\hline \multirow{2}{*}{$\begin{array}{l}\text { Chain length of the } \\
\text { amphiphiles }\end{array}$} & \multicolumn{2}{|c|}{ Compound } & \multirow{2}{*}{$\begin{array}{l}\text { Limiting area per } \\
\text { molecule }\left(\AA^{2}\right)\end{array}$} & \multirow{2}{*}{$\begin{array}{c}\text { Max pressure } \\
\text { sustained }(\mathrm{mN} / \mathrm{m})\end{array}$} \\
\hline & Double-tailed & Hexa-tailed & & \\
\hline \multirow[t]{2}{*}{$\mathrm{C}_{10}$} & $\mathbf{L}_{4}$ & \multirow{3}{*}{$\mathbf{L}_{10}$} & 150 & 36 \\
\hline & & & 675 & 32 \\
\hline \multirow[t]{2}{*}{$\mathrm{C}_{12}$} & $\mathbf{L}_{5}$ & & 148 & 36 \\
\hline & & \multirow[t]{2}{*}{$\mathbf{L}_{11}$} & 655 & 34 \\
\hline \multirow[t]{2}{*}{$\mathrm{C}_{16}$} & $\mathbf{L}_{6}$ & & 132 & 39 \\
\hline & & \multirow[t]{2}{*}{$\mathbf{L}_{12}$} & 540 & 44 \\
\hline \multirow[t]{2}{*}{$\mathrm{C}_{22}$} & $\mathbf{L}_{7}$ & & 121 & 40 \\
\hline & $\mathbf{L}_{-}$ & $\mathbf{L}_{13}$ & 435 & $\begin{array}{l}50 \\
25\end{array}$ \\
\hline $\mathrm{C}_{18}$ (one unsaturation) & $\mathrm{L}_{8}$ & \multirow[t]{2}{*}{$\mathbf{L}_{14}$} & 520 & $\begin{array}{l}35 \\
41\end{array}$ \\
\hline \multirow{2}{*}{$\mathrm{C}_{18}$ (two unsaturations) } & \multirow[t]{2}{*}{$\mathbf{L}_{9}$} & & 125 & 33 \\
\hline & & $\mathbf{L}_{15}$ & 500 & 42 \\
\hline
\end{tabular}

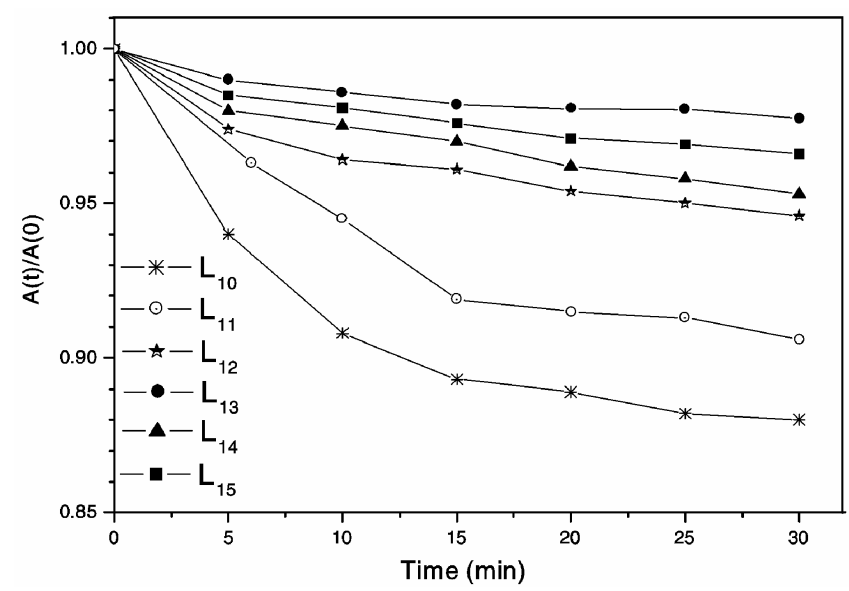

Figure 4. Comparison of the stability of the monolayer at the air-water interface for the amphiphiles, $\mathbf{L}_{10}-\mathbf{L}_{15}$.

part. But for longer chain lengths, higher surface pressure can be sustained by hexa-tailed compared to corresponding double-tailed amphiphiles.

The limiting molecular area obtained from extrapolating the liquid expanded regions of the pressure-area isotherms are shown in table 1. For example, in case of $\mathbf{L}_{7}$ it is $121 \AA^{2}$ and for $\mathbf{L}_{13}$ it is $435 \AA^{2}$. These values correspond to the molecular radius of the cryptand headgroup $6 \cdot 2 \AA\left(\mathbf{L}_{7}\right)$ and $11.8 \AA\left(\mathbf{L}_{13}\right)$ for tri-cryptand head-group. All the cryptand head-group's radii lie in the range $6 \cdot 2-$ $6.9 \AA$ and we speculate that the values are $11.8-14.6 \AA$ for the tri-cryptand systems. In comparison, the average radius of the cryptand headgroup calculated from the pressure-area isotherms for single-headed single-tailed amphiphiles were in the range of 5.2-5.6 $\AA$ (Das et al 1997) and of triple-headed, triple-tailed amphiphiles were found to be in the range of 6.4-6.7 $\AA$ (Das et al 2000). From X-ray crystallographic studies of the latter type of amphiphiles, the average radius of the cryptand headgroup is about $5.7 \AA$ (Ghosh et al 1996). However, a realistic model can only be obtained from studies that provide surface structures.

The stability of the monolayer is found to be dependent upon the length of the hydrocarbon chain. $\mathbf{L}_{7}$ and $\mathbf{L}_{13}$ were found to be most stable and $\mathbf{L}_{4}$ and $\mathbf{L}_{10}$ being least stable among the double-tailed and hexa-tailed amphiphiles, respectively. Figure 4 provides a typical scale presenting the ratio between the area of the monolayer determined at time, $t$, at a constant pressure $\Pi, A(t)$, and at time, $t=0, A(0)$, for hexa-tailed amphiphiles. The liquid expanded region in each case indicates that each amphiphile is undergoing rapid re-organization and reorientation. Also, hexa-tailed amphiphiles are more stable than their corresponding double-tailed amphiphiles having same alkyl chain length. Hexa-tailed amphiphiles, $\mathbf{L}_{12}-\mathbf{L}_{15}$ are found to be able to sustain a pressure of $25 \mathrm{mNm}^{-1}$ for up to $30 \mathrm{~min}$ without any significant area loss while $\mathbf{L}_{10}-\mathbf{L}_{11}$ are found to be quite unstable at the same target pressure and continuous decrease in area with time is observed in each case. This observation indicates that to form a stable monolayer, there should be a balance between hydrophilic head-group and hydrophobic chain.

None of the amphiphiles show any significant width in the hysteresis curve on successive compression and expansion, a representative of which is shown in figure 5. Under our experimental conditions, palmitic acid (used as the control) does not show any hysteresis as well. Width of the hysteresis curve observed in such experiments is due to multi-layering or collapsing of the film. Thus, these amphiphiles are capable of forming robust monolayers, which can withstand reversible compression and expansion without any major change in the monolayer structure.

In monolayer formation, the speed of compression is an important parameter. At high speed, isotherms suffer from kinetic effects, which are related to the nucleation of the condensed phases and to the difficulty of the condensed domain to coalesce (Castillo et al 1996). Several 
experiments are performed at different compression speeds. It is found that when a monolayer is compressed at a slow speed of $20-50 \mathrm{~cm}^{2} / \mathrm{min}$, the isotherms are slightly steeper compared to the situation when the barrier speed is $250 \mathrm{~cm}^{2} / \mathrm{min}$. This implies that when barrier speed is slow, the molecules are getting time to undergo reorganization and are packing more effectively. However, the isotherms that are obtained by performing the film compression in a quasi-static mode (i.e. compression at $50 \mathrm{~cm}^{2} \mathrm{~min}^{-1}$ and waiting time, $2 \mathrm{~min}$ ) are same as that of the continuous one.

In the case of hexa-tailed amphiphiles, there is no effect of subphase $\mathrm{pH}$ on the monolayer stability and limiting area/molecule. This is due to the fact that neither the amide nitrogens nor the bridged nitrogens can be protonated when an acid is added to the cryptand/amphiphile.

With concentrated spreading solutions, there is always a chance of formation of multi-layers (Das et al 2000) specially under high surface pressures. So, we have varied the concentration of the spreading solutions from $1-5 \mathrm{mg} / \mathrm{ml}$. But we do not observe any multilayer film on the water surface apparently owing to the lack of extensive cohesive forces amongst the amphiphilic molecules. At higher concentration, however, the film collapses as expected.

The behaviours of the mixed Langmuir monolayers also have been studied. The surface pressure (П) vs area per molecule $\left(\AA^{2}\right)$ isotherm for mixed cryptand based amphiphiles and stearic acid was investigated in different molar ratios at a barrier speed of $100 \mathrm{~cm}^{2} / \mathrm{min}$. These studies provide much insight into existing interactions between the constituents of the mixed monolayers. Mixed monolayers can be categorized into three types: (i) complete miscibility, (ii) total phase separation, and (iii) partial miscibility. For two component systems of non-interacting molecules the average area per molecule of the mixed system, $A_{12}$, is given by a relation suggested by several workers (Gains 1966; Datta 1997)

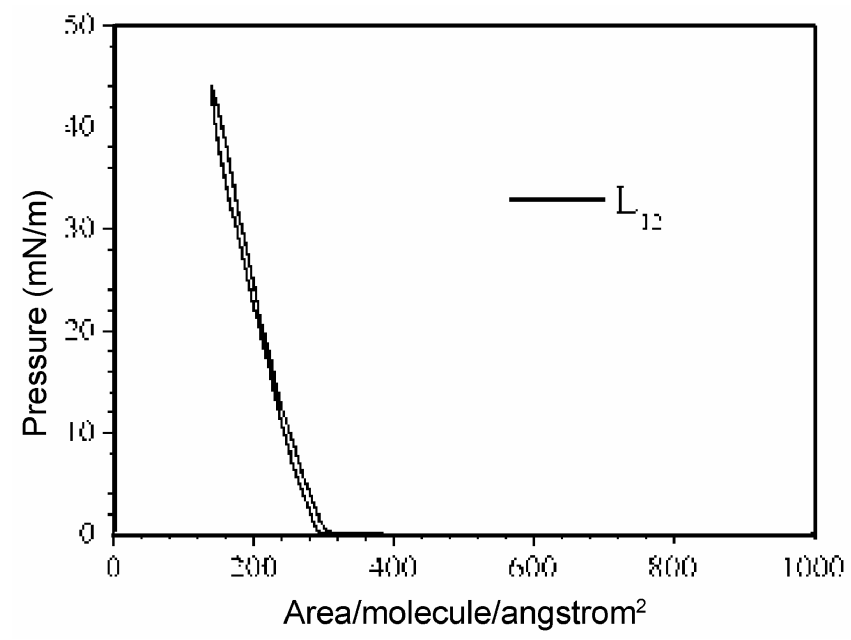

Figure 5. Representative successive compression and expansion cycles of $\Pi-A$ isotherm.

$$
A_{12}=N_{1} A_{1}+N_{2} A_{2} \text {, }
$$

where $N_{1}, A_{1}$ and $N_{2}, A_{2}$ are the mole fractions and the area per molecules at zero pressure of the first and second components, respectively. $A_{12}$ are the average area per molecule at zero pressure of the mixed monolayer of the two component systems. When stearic acid and an amphiphile is taken in 1:1 molar ratio, the experimentally obtained area per molecule of the mixed system is greater than the sum of the area of the pure components, which suggest (Dutta et al 1996) the existence of a repulsive interaction between the stearic acid and the amphiphile. When mixed with stearic acid in $1: 1$ molar ratio (a) the maximum pressure sustained increases by $10 \%$, (b) expansion of isotherm is obtained indicating repulsive interaction between stearic acid and amphiphile, and (c) the monolayer becomes more stable. When stearic acid and an amphiphile are taken in 3:1 molar ratio, the isotherm in all the three cases show two distinct collapse pressures. The monolayer first starts collapsing at a lower collapse pressure compared to that of the pure amphiphilic molecules and when the compression is continued, the surface pressure again starts rising until the higher collapse pressure corresponding to the stearic acid is reached. This

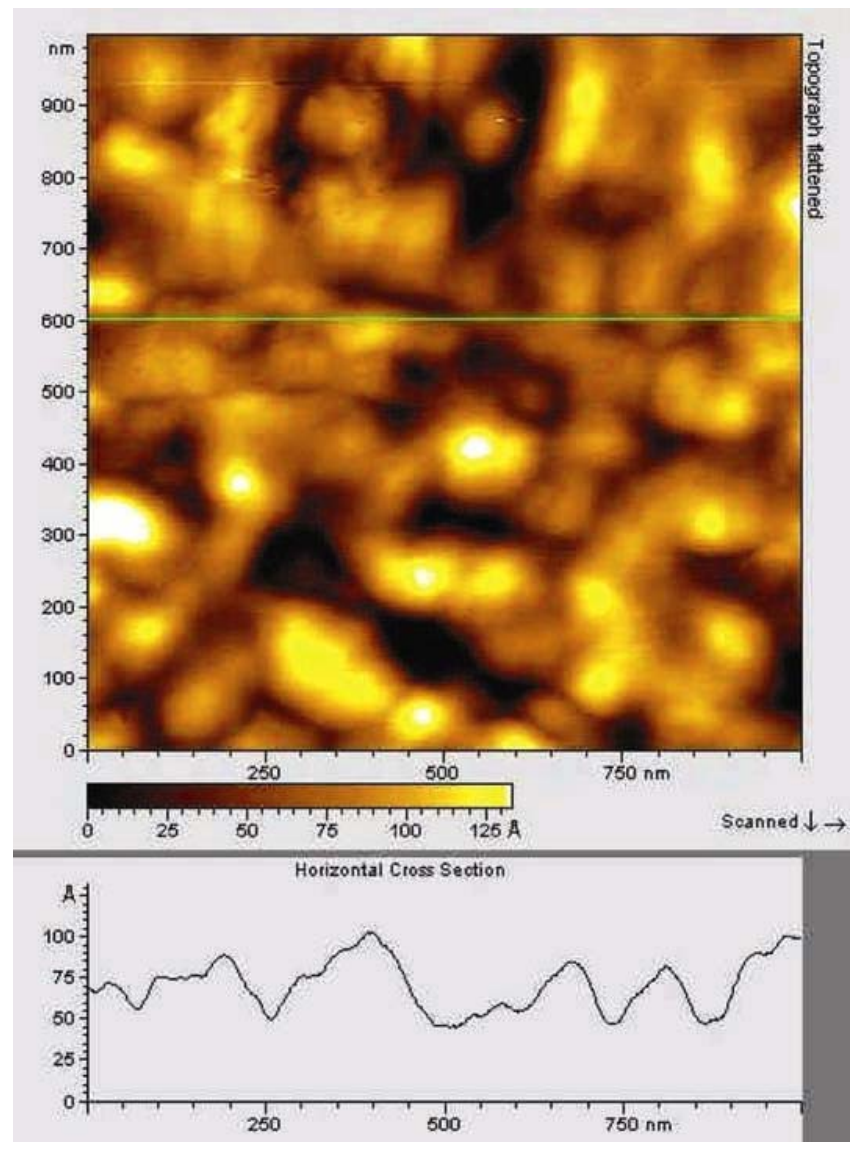

Figure 6. $\mathrm{AFM}$ image of 50 layers of $\mathbf{L}_{13}$ at a resolution of $1000 \mathrm{~nm}$. 
result indicates that when stearic acid concentration is increased the two components become immiscible and exist as separate domains (Roberts 1978). In this case the monolayer is stable for more than $1 \mathrm{~h}$ at a target pressure of $25 \mathrm{mNm}^{-1}$ without any significant area loss.

\subsection{Deposition of Langmuir-Blodgett films and their characterization}

The monolayers at the air-water interface are transferred onto quartz plates to get multi-layered films. Deposition takes place at each downward and upward dip. Dipping speed was kept $4 \mathrm{~mm} / \mathrm{min}$ for downward stroke and $5 \mathrm{~mm} / \mathrm{min}$ for upward stroke. Between subsequent dips, the sample was allowed to dry in air for $15 \mathrm{~min}$ to avoid retransferring of the last deposited monolayer to the subphase. We have deposited amphiphile $\left(\mathbf{L}_{13}\right)$ having chain length of $\mathrm{C}_{22}$. The surface pressure was kept at $15 \mathrm{mN} / \mathrm{m}$ for deposition of the LB film. The transfer ratio for upward and downward dip was comparable to each other, which suggests a Y-type film deposition.

Study of LB film by non-contact AFM (figure 6) indicates a well-formed film. The thicknesses of the LB films were measured as: 24 layers, $300 \AA$; 35 layers, $720 \AA$ and 50 layers, $860 \AA$. An examination of these numbers indicate that the film formed is ordered atleast up to 35 th layers and beyond that it becomes disordered.

\section{Conclusions}

Both the double- and hexa-tailed amphiphiles form stable robust monolayers at the air-water interface. The present studies indicate that a balance between size of the headgroup and hydrophobic chain-length is necessary for cryptand-based amphiphiles to behave well at the air-water interface. Stability of the monolayer i.e. the decrease in area of the monolayer with time is higher for the hexatailed amphiphiles compared to double-tailed ones. Hexatailed amphiphiles can also form stable and uniform LB films up to almost 36 layers and also form spontaneous giant vesicles in ethanol-water dispersion. The LB technique can be effectively utilized to have films with cryptand-based amphiphiles for having materials with desired interfacial properties. This can serve as a basic concept to understand biological functions and can offer a key in developing new types of functionalized materials.

\section{Acknowledgements}

Financial support received by one of the authors (PKB) from the Department of Science and Technology, New Delhi (grant No. SR/S5/NM-38/2003) is gratefully acknowledged.

\section{References}

Abraham B M, Ketterson J B, Miyano K and Kueny A 1981 J. Chem. Phys. $\mathbf{7 5} 3137$

Castillo R, Ramos S, Cruz R, Martinez L F and Ruiz-Garcia J 1996 J. Phys. Chem. 100709

Das G, Ghosh P, Bharadwaj P K, Singh U and Singh R A 1997 Langmuir 133582

Das G, Bharadwaj P K, Singh U, Singh R A and Butcher R J 2000 Langmuir 161910

Dutta A K 1997 J. Phys. Chem. B101 569

Dutta A K, Mishra T N and Pal A J 1996 Langmuir 12459

Foerster S and Antonietti M 1998 Adv. Mater. 10195

Ghosh P, Sengupta S and Bharadwaj P K 1998 Langmuir 145712

Ijiro K, Matsumoto J, Morisie M and Shimomura M 2002 Int. J. Nanosci. 1597

Lazzari M, Rodriguez-Abreu C, Ribas J, Lopez Q and Arturo M 2006 J. Nanosci. Nanotechnol. 6892

Le Bourder T, Maury O, Bondon A, Costuas K, Amouyal E, Ledoux I, Zyss J and Le Bozec H 2003 J. Am. Chem. Soc. 12312284

Nakane Y and Kubo I 2004 Chem. Sensors 20616

Ragunathan K G and Bharadwaj P K 1992 Tetrahedron Lett. 33 7581

Roberts G 1978 Langmuir-Blodgett films (New York: Plenum Press)

Ulman A 1991 An introduction to ultrathin films: From Langmuir-Blodgett to self-assembly (San Diego: Academic Press) 